

\section{Sumário}

I. Dossiê Especial: History of International Law ...................................1

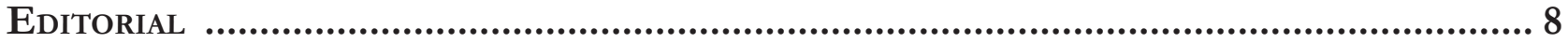

What does it mean to apply history in international law studies? ....................................................... 8

Arthur Roberto Capella Giannattasio

SuR LA NATURE DU Droit ISLAMIQUe............................................................................14

Hocine Benkheira

Islamic Shari’a Law, History and Modernity: Some Reflections .................................25 Suleiman A. Mourad

The (Un)practical Secularization Process: International Law and Religion as So-

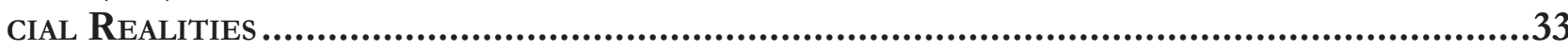

Douglas de Castro

BRAZILIAN LITERATURE ON INTERNATIONAL LAW DURING THE EMPIRE REGIME. OR THE DIFFUSION OF INTERNATIONAL LAW IN THE PERIPHERIES THROUGH APPROPRIATION AND ADAPTATION.

Airton Ribeiro da Silva Júnior

Natural, POSitivo, romano E Universal? INVESTigaÇão SObre O Direito das GENTES EM

Tomás de Aquino

Rafael Zelesco Barretto

II. Artigos sobre outros temas

VINCULAÇÃO DOS DIREITOS ECONÔMICOS, SOCIAIS E CULTURAIS: UMA DISCUSSÃO DO DESENVOLVImento humano com base no conceito de Amartya Sen sobre o mínimo existencial.....99

Natalia Mascarenhas Simões Bentes e Yasmim Salgado Santa Brígida

A NOVA LeI de MigraÇão E A PROTEÇão CONFERIDA AO APÁtrida: ALINHAMENTO BRASILEIRO AO PADRÃO INTERNACIONAL DE DIREITOS HUMANOS

Pedro Henrique de Faria Barbosa e Sylvio Loreto

E se o Supremo Tribunal Federal (STF) restabelecer a vigência da Convenção n. 158 
da Organização Internacional do Trabalho (OIT) na ordem Jurídica brasileira? SoBRE UMA POSSÍVEL REVIRAVOLTA, PELA VIA DO DIREITO INTERNACIONAL, DAS LEIS TRABALHISTAS BRASILEIRAS 138

Daniel Damasio Borges

JULGADOS DA CORTE INTERAMERICANA SOBRE CASOS BRASILEIROS E POLÍTICAS PÚBLICAS: REFLEXÕES ACERCA DE POSSÍVEIS INFLUIÇÕES 165

Rafael Osvaldo Machado Moura

CREATING BRIDGES BETWEEN INTERNATIONAL RELATIONS THEORY AND INTERNATIONAL HUMAN RIGHTS LAW: CONSTRUCTIVISM AND THE ROLE OF BRAZIL IN THE INTER-AMERICAN SYSTEM OF HUMAN RIGHTS 179

Ismael Francisco de Souza, Luciana Rocha Leme e Erick da Luz Scherf

Justiça de transição na Argentina e o Sistema Interamericano de Direitos Humanos: uMa ANÁlise do CASo Luis Muiña (“REgRa 2x1”) 199

Emilio Peluso Neder Meyer e Jessica Holl

A legalidade e legitimidade da INTERVEnÇão humanitÁria: UMA MEDIDA AINDA NECESSÁRIa.219 Natália Caye Batalha Boeira

O Acordo de Escazú E o ACESSo À INFORMaÇão AMbiental no Brasil. 252 Érica Bezerra Queiroz Ribeiro e Bruno Amaral Machado

Dos POVOS NATIVOS AO SURGIMENTO DOS MOVIMENTOS SOCIAIS: INFLUÊNCIAS DOS DISCURSOS JURÍDICOS, RELIGIOSOS E MÉDICOS PARA A CONSTRUÇÃO DO CONCEITO DE HOMOSSEXUALIDADE NO BRASIL .267 Bruno Rafael Silva Nogueira Barbosa e Robson Antão de Medeiros

Aspectos Jurídicos da PARTicipaÇão dA UNião Europeia NA OMC: COMPREENDENdo SUTILEZAS DE UM DELICADO ENLACE. 291

Camilla Capucio

Path to judicial activism? The use of "Relevant rules of international law" by the WTO Appellate Body

Mariana Clara de Andrade

LEVEZA E PESO NA MEDIAÇÃO COMERCIAL INTERNACIONAL: O CONTEÚDO JURÍDICO DO ACORDO CORPORATIVO MEDIADO E SUA INCORPORAÇÃo PELO DiREITO BRASILEIRO .324 Henrique Lenon Farias Guedes 
JURISDIÇÃO INTERNACIONAL E AS DIFICULDADES DE EXECUÇÃO DE SENTENÇAS INTERNACIONAIS NO BRASIL

Nevitton Vieira Souza

O DEVER DE COOPERAÇÃo NOS CONTRATOS DE VENDA INTERNACIONAL DE MERCADORIAS: PRESSUPOSTOS TEÓRICOS E REPERCUSSÕES PRÁTICAS DA CLÁUSULA GERAL DA BOA-FÉ OBJETIVA PARA A APLICAÇÃo DA CISG .358

Angelo Gamba Prata de Carvalho

A DiMENSÃo JURÍdiCA DO IMPERIALISMO NA (DES)ORDEM GLOBAL CAPITALISTA: UMA ANÁLISE COM BASE NA CRÍTICA MARXISTA AO DIREITO INTERNACIONAL E ÀS RELAÇÕES POLÍTICO-ECONÔMICAS DE DOMINAÇÃO E DEPENDÊNCIA.

Thomaz Delgado De David, Maria Beatriz Oliveira da Silva e Rosane Beatris Mariano da Rocha Barcellos Terra

A participaÇão de Brasil e Estados Unidos na formulação das regras multilaterais do

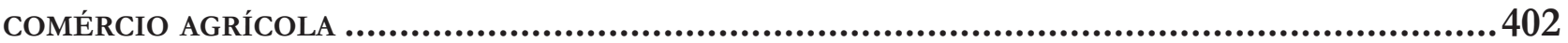

Vera Thorstensen, Vivian Daniele Rocha Gabriel e Alebe Linhares Mesquita

A galáxia lex e a construÇão de um Sistema jurídico transnacional ........................ 441

Eugênia Cristina Nilsen Ribeiro Barza e Jéssyka Maria Nunes Galvão

Has the Ability of Truth Commissions to Recommend Amnesty Been Effective in Enhancing Perpetrator Cooperation? 453 Jeremy Sarkin

A CONCEPTUAL PAPER ON THE POLICY-FRAMEWORK THAT MIRRORS THE DYNAMIC LINK BETWEEN Human Security, Social Protection and Safety Nets, and Food and Nutritional Security: The Case of the "Gulayan sa Paaralan Program", the Philippines.... 478 Renato Lagapa Base

INCENTIVISING SMALLHOLDER FARMER LIVELIHOODS AND CONSTRUCTING FOOD SECURITY THROUGH HOME-GROWN SCHOOL FEEDING: EVIDENCE FROM NORTHERN GHANA .491

Clement Mensah

Policy COHERENCE In THE IMPLEMENTATION OF THE 2030 AgENDA FOR SUSTAINABLE DEVELOpment: the Brazilian School Feeding Programme Case Study .506 Mariana Werlang Girardi 


\title{
Julgados da corte interamericana sobre casos brasileiros e políticas públicas: reflexões acerca de possíveis influições*
}

\author{
Sentences of the Inter-American Court \\ on brazilian cases, and public policies: \\ reflections on possible influences
}

Rafael Osvaldo Machado Moura**

\section{Resumo}

À luz de noções de políticas públicas, o vertente trabalho analisa o papel desempenhado pela Corte Interamericana de Direitos Humanos em relação ao Estado brasileiro. O Tribunal Interamericano tem competência para interpretar e aplicar por último as disposições da Convenção Americana de Direitos Humanos e de outros tratados regionais, a fim de evitar e/ou reparar violações a direitos e garantias previstos em âmbito regional, exercendo, assim, funções de controle de convencionalidade sobre a conduta das instituições públicas nacionais. O problema que este artigo se propõe a responder é: tem a Corte Interamericana interferido na criação e/ou modificação de políticas públicas a serem implementadas no Brasil? Em caso positivo, este trabalho classificará os mencionados julgados da Corte Interamericana, a partir de diretrizes conceituais, da tipologia e do ciclo das políticas públicas.

Palavras-chave: Direitos Humanos. Corte Interamericana. Políticas Públicas.

* Recebido em: 27/09/2018

Aprovado em: 07/10/2018

** Doutorando e Mestre em Direito, na linha de pesquisa Justiça, Democracia e Direitos Humanos, pelo PPGD da Pontíficie Universidade Católica do Paraná. Promotor de Justiça do Ministério Público do Paraná. Coordenador do Núcleo de Igualdade Étnico-Racial - NUPIER -, do Eixo Política Agrária e do Núcleo de Direitos LGBT, todos do Centro de Apoio Operacional das Promotorias de Justiça de Proteção aos Direitos Humanos, em Curitiba. Membro colaborador da Comissão de Direitos Fundamentais do Conselho Nacional do Ministério Público (CNMP/GT4). E-mail: rafa. osmoura@gmail.com

\section{Abstract}

Within the framework of public policies, the present work analyzes the role played by the Inter-American Court of Human Rights in relation to brazilian State. The Inter-American Court is an autonomous judicial institution whose purpose is the application and interpretation of the American Convention on Human Rights, in order to avoid violation of human rights, and exercising conventionality control over the domestic institutions and rules. The question that this article proposes to answer is: has the Inter-American Court influenced in the creation of the brazilian public policies? If so, this paper will classify that decisions based on the stardarts of public policies.

Keywords: Human Rights. Inter-American Court. Public Policies. 


\section{INTRODUÇÃO}

O tema políticas públicas tem ganhado, cada vez mais, espaço nas discussões acadêmicas, chegando a ponto de ser tratado como disciplina solo. Ademais, tem gerado repercussões a serem estudadas na área do Direito, pois o Estado legislador, que, em sua acepção liberal clássica consistia em um mero definidor de direitos individuais, passou a funcionar como um promotor de metas ou finalidades coletivas, de modo que as leis em sentido amplo passaram a ser também instrumento de governo, impondo tarefas a serem empreendidas pelo poder executivo. Além disso, tal fenômeno colocou o sistema de justiça no centro dos debates acerca das políticas públicas, em razão de ser mecanismo de implementação das leis.

A atuação do governo, nesse novo contexto, tem que corresponder às coordenadas definidas pelo Direito, daí advindo a importância em se trabalhar normativamente com o conceito de políticas públicas.

Portanto, por ter esse caráter marcadamente jurídico, o sistema de justiça tem trabalhado com os marcos normativos que estabelecem as políticas públicas, podendo interpretar e aplicar as normas respectivas, além, é claro, de realizar controle de constitucionalidade.

Assim, é possível falar-se em políticas públicas definidas, em certa medida — no âmbito permitido pelas normas jurídicas, o que por vezes também indevidamente se dá fora de tal margem —, pelo sistema de justiça, isto é, pelo judiciário provocado por Ministério Público e advogados em geral.

De outro lado, hoje não se pode mais falar apenas no sistema de justiça doméstico de cada estado, mas também nos internacionais que irradiam efeitos em casos de violação de direitos por parte dos Estados-nacionais. É o caso do Sistema Interamericano de Direitos Humanos, formado pelas Comissão e Corte Interamericanas, com atribuição para processar e julgar violações de direitos humanos cometidas pelos Estados partes da Convenção Americana de Direitos Humanos e outros tratados no âmbito interamericano. Tais órgãos internacionais podem declarar a ocorrência de agressão a direitos humanos previstos nos documentos internacionais respectivos, bem como condenar o Estado violador a, entre outras, indenizar as vítimas, adotar medidas para evitar a repetição das violações similares, reparar os danos de diversas formas e reabrir investigações criminais.
Assim, surge a hipótese de que as manifestações da Corte Interamericana estejam a criar determinadas políticas públicas nas áreas ligadas aos temas por ele julgados.

Portanto, o problema do presente artigo, de modo mais delimitado, visa responder ao seguinte questionamento: têm as decisões da Corte Interamericana, proferidas em face do Brasil, criado ou influenciado políticas públicas a serem executadas em âmbito doméstico?

Para responder à indagação, num primeiro momento, será apresentado o conceito de políticas públicas, suas características e principais formas de classificação. A seguir, será delineado o que vem a ser o Sistema Interamericano. Por fim, serão apresentadas, sucintamente, as sete decisões proferidas com base em casos ocorridos em solo brasileiro, analisando-as a partir dos conceitos e critérios que estabelecem o conceito de políticas públicas e suas classificações.

\section{Políticas públicas}

Para evitar confusões terminológicas, vale salientar as diferenças, tal como fazem os anglo-saxões, das duas acepções semânticas do termo política - "politics" e "policy". O primeiro tem a ver com política como meio para se obter o poder, ao passo que o segundo se refere ao modo como se exercerá o poder obtido, adotando-se um conjunto de decisões para a resolução de conflitos em torno da alocação de bens e serviços públicos ${ }^{1}$ Essa última acepção trata da política pública, objeto deste capítulo, cujas características serão detalhadas a seguir, mormente em relação ao seu conceito, aos seus diferentes tipos e ao seu ciclo de execução.

Outro ponto a ser abordado preliminarmente a respeito das políticas públicas tem a ver com qual dos poderes estatais tem a competência para elaborá-las, executá-las e avaliá-las. Isso porque, cada vez mais, no Brasil o poder judiciário tem sido chamado para, em supostas omissões ou atuações antijurídicas dos poderes legislativo e/ ou executivo, suprir a atuação destes. É exemplificativa dessa atuação do Judiciárioa utilização da ação de descumprimento fundamental (ADPF) nú-

1 BUCCI, Maria Paula. O conceito de política pública em direito. In: BUCCI, Maria Paula (Org.). Políticas Públicas, reflexões sobre o conceito jurídico. São Paulo: Saraiva, 2006. p. 14. 
mero 45-5, em que o Supremo Tribunal Federal, na voz do Ministro Celso de Mello, entendeu que:

é certo que não se inclui, ordinariamente, no âmbito
das funções institucionais do Poder Judiciário - e
nas desta Suprema Corte, em especial - a atribuição
de formular e de implementar políticas públicas
José Carlos Vieira de Andrade, Os direitos
fundamentais na Constituição Portuguesa de 1976,
p. 207 , item n. 05, 1987, Almedina, Coimbra), pois,
nesse domínio, o encargo reside, primariamente, nos
Poderes Legislativo e Executivo. Tal incumbência,
no entanto, embora em bases excepcionais, poderá
atribuir-se ao Poder Judiciário, se e quando os
órgãos estatais competentes, por descumprirem os
encargos político-jurídicos que sobre eles incidem,
vierem a comprometer, com tal comportamento, a
eficácia e a integridade de direitos individuais e/ou
coletivos impregnados de estatura constitucional,
ainda que derivados de cláusulas revestidas de
conteúdo programático. ${ }^{2}$

Assim, no Brasil tem o poder judiciário não somente controlado incorreções nas políticas públicas já desenhadas e implementadas pelos demais poderes, como também, às vezes, tem formulado e determinado a execução daquelas.

\subsection{Definição de política pública}

Há vários conceitos a respeito de política pública. Um deles, mais conciso, é apresentado por Leonardo Secchi, segundo o qual política pública trata-se de uma diretriz elaborada para enfrentar um problema público. Nessa perspectiva, surgem dois elementos de tal definição: intencionalidade pública e um problema público. ${ }^{3}$

Outra definição, mais tradicional, enfatiza os aspectos relacionados a quem se beneficia das decisões públicas, bem como quais os motivos por trás de cada ação governamental. ${ }^{4}$

Há, ainda, um terceiro, a enfatizar que política pública refere-se às ações do poder público e às avaliações destas, que podem gerar mudança de postura governamental .5 A esse conceito agregam-se imprescindíveis

2 BRASIL. Supremo Tribunal Federal. Acórdão na ADPF n. 45. Tribunal Pleno. Relator: Mello, Celso de. Brasília, 29 abril 2004. Disponível em: www.stf.jus.br/portal/acordaodecisaoRelevante/ verDecisaoRelevante.asp? ministro $=28 \&$ retorno $=$ true. Acesso em: 5 out. 2017.

3 SECCHI, Leonardo. Politicas Públicas: conceitos, esquemas de análise, casos práticos. São Paulo: Cengage Learning, 2011.

4 SOUZA, Celina. Políticas públicas: uma revisão da literatura. Sociologias, Porto Alegre, ano 8, n. 16, p. 20-45, jul./dez. 2006.

5 SOUZA, Celina. Políticas públicas: uma revisão da literatura. So- características das políticas públicas, sobretudo a respeito de cada uma das etapas de formulação das ações governamentais, tais como metas a serem atingidas e processos de análise crítica. Assim, políticas públicas abrangem programas, metas, objetivos, ações e revisões ${ }^{6}$ , e envolvem processos subsequentes após sua decisão e proposição, ou seja, implica, também, implementação, execução e avaliação. Esse conceito afigura-se o mais pertinente.

Importante registrar, também, que a razão de ser da elaboração de estudos em torno das políticas públicas, bem como da consolidação de leis a seu respeito, repousa na ideia de que, em um Estado democrático de Direito, toda a ação governamental deve ser produzida de modo científico e passível de verificação e escrutínio por pessoas independentes.

Logo, a política pública, após a identificação de um problema que chegou ao sistema político (politics), por meio da sociedade política (polity), visa corrigir aquele, colocando em marcha as instituições/regras que darão forma e empreenderão um conjunto de decisões — um programa - a respeito de determinado tema a ser enfrentado, cujos consectários, diretos e indiretos, posteriormente serão sopesados.

\subsection{Diferentes tipos de políticas públicas}

A forma de classificação de políticas públicas utilizadas neste artigo refere-se à criada por Theodore Lowi, segundo a qual cada tipo de política pública impõe um tipo de relação política, com consequências próprias sobre a sociedade. ${ }^{7}$

A tipologia em questão trabalha com quatro categorias de políticas públicas, a saber: a) políticas públicas distributivas; b) políticas públicas redistributivas; c) políticas públicas regulatórias; e d) políticas públicas constitutivas.

O primeiro item tem a ver com as ações estatais que visam beneficiar um conjunto de pessoas, sem, contudo, afetar um outro grupo social. Exemplos disso são os subsídios e isenções fiscais.

ciologias, Porto Alegre, ano 8, n. 16, p. 20-45, jul./dez. 2006. p. 20-45. 6 RODRIGUES, Marta M. Assumpção. Politicas Públicas. São Paulo: Publifolha, 2011. (Coleção Folha Explica).

7 SOUZA, Celina. Políticas públicas: uma revisão da literatura. Sociologias. Porto Alegre, ano 8, n. 16, jul./dez. 2006. 
O segundo consiste na concessão de benefícios a um determinado grupo de pessoas, o que ocorre, todavia, diferentemente do que se dá nas políticas públicas distributivas, com a afetação de outros grupos definidos, que perdem parcela de seus proveitos. As cotas raciais e a reforma agrária são exemplos dessa espécie de políticas públicas.

No terceiro item, são tratadas as atividades estatais que promovem determinados padrões de conduta das pessoas, com imposição de normatizações e, ao mesmo tempo, de fiscalizações das atividades disciplinadas.

Por fim, no que toca às políticas públicas constitutivas, trabalha-se com a criação de regras eleitorais, determinando a tomada do poder político por parte de grupos sociais, bem como de normas que disciplinam a participação da sociedade civil nas atividades governamentais, inclusive na elaboração de políticas públicas. Portanto, nesta última espécie, trata-se das políticas públicas acerca da definição e implementação de outras políticas públicas.

\subsection{Ciclo de políticas públicas}

De acordo com Leonardo Secchi, as fases que compõe o ciclo de políticas públicas, isto é, as etapas pelas quais nascem, desenvolvem-se e são avaliadas, são as que segue: a) definição de agenda; b) identificação de alternativas, avaliação das opções e escolha das opções; c) implementação; e d) reavaliação. ${ }^{8}$

O primeiro subitem tem por objetivo responder como os governos elaboram a sua pauta de prioridades, cuja resposta passa pelos problemas públicos, pelos processos políticos propriamente ditos, que também funcionam como catalisadores dos problemas (reais ou não) que surgem no ambiente do debate público e, por fim, pelos atores, participantes do debate público, que podem ser desde agentes políticos (em sentido estrito e amplo), partidos políticos, meios de comunicação, grupos de pressão da sociedade civil, academia, entre outros. Portanto, decidem-se quais questões serão objeto de alguma política pública, o que se verifica, na área da saúde, a na opção por trabalharem-se questões específicas de um determinado tipo de patologia.

Já na segunda etapa, buscam-se alternativas para

8 SECCHI, Leonardo. Políticas Públicas: conceitos, esquemas de análise, casos práticos. São Paulo: Cengage Learning, 2011. p. 18. enfrentamento dos problemas apontados, as quais, em seguida, são ponderadas para que se escolha a proposta mais adequada às finalidades eleitas.

Nesse ponto, aplica-se o modelo "garbage can", criado por Cohen, March e Olsen (1972), de acordo com o qual as decisões relacionadas às políticas públicas se dão de modo não estritamente racional, tanto pela limitação das informações no momento das deliberações, como pelos muitos interesses, às vezes colidentes, defendidos pelos participantes dos processos de escolha. Assim, muitas das decisões são tomadas por meio de um sistema de tentativa e erro, de modo que as opções preteridas ficam em uma "lata de lixo" temporária, podendo ser resgatadas a qualquer momento, quando se concluir que a solução adotada, num primeiro momento, não se mostrou adequada. ${ }^{?}$

$\mathrm{Na}$ terceira fase, no momento da execução da política pública adotada, os processos, as rotinas e as regras são colocados em prática. A partir desse momento, devem-se visualizar os erros praticados antes e durante a tomada de decisão, mormente em relação aos objetivos traçados, com metas acima ou abaixo do possível. ${ }^{10}$

Por fim, na quarta fase, que se inicia durante a execução, mas tem o seu ponto alto após o término da realização da política pública, avaliam-se os resultados principais e assessórios gerados. Subdivide-se da seguinte maneira essa etapa: a) Avaliações de esforços: levam-se em conta todos os recursos destinados à política pública, o que envolve não apenas os gastos financeiros diretos como os de pessoal, de comunicação, de transporte, de material, etc. Busca-se transformar todos esses fatores em valores monetários, para que seja possível aferi-los. b) Avaliações de desempenho: consideram-se os produtos produzidos pelas ações empreendidas, o que pode ser, por exemplo, o número de leitos criados ou reformados, o número de salas de aulas em funcionamento. c) Avaliações de processo: põe-se em consideração as regras e os procedimentos utilizados, buscando-se saber se poderiam ser mais eficientes e diretos. d) Avaliações de eficiência: visa-se responder se os produtos gerados são proporcionais aos insumos despendidos. e) Avaliações de adequação de eficácia: analisa-se o desempenho

9 COHEN, M. D.; MARCH, J. G.; OLSEN. A garbage can model of organizational choice. Administrative Science Quarterly, Ithaca (NY), v. 17, n. 1, p. 1-25, 1972.

10 SECCHI, Leonardo. Políticas Públicas: conceitos, esquemas de análise, casos práticos. São Paulo: Cengage Learning, 2011. 
da política pública em vista das metas estabelecidas, a fim de saber se os resultados propostos inicialmente foram atingidos, tais como a melhoria dos índices de saúde e educação. ${ }^{11}$

\section{Sistema Interamericano de Direitos Humanos}

No ano de 1945, surgiu a necessidade de criação dos mecanismos de proteção dos direitos fundamentais dos indivíduos em nível internacional, a fim de evitarem-se novos acontecimentos trágicos, tais como os ocorridos na Segunda Guerra Mundial, razão pela qual foi gerado, entre outros, o Sistema Interamericano de Direitos Humanos.

O Sistema Interamericano nasceu em 1948, por intermédio da Carta de Bogotá, a partir da criação da Organização dos Estados Americanos (OEA). Na mesma data, concebeu-se a Declaração Americana de Direitos e Deveres do Homem (DADDH), documento anterior, inclusive, à Declaração Universal dos Direitos Humanos (DUDH), datada de dezembro do mesmo ano. ${ }^{12}$ De acordo com o Documento, o Sistema Interamericano deveria ser posteriormente fortalecido, na medida do possível com a elaboração de tratados com força vinculante obrigatória, quando as circunstâncias fossem mais propícias. À época, a DADDH foi elaborada para funcionar como mera carta de intenções, sem valor vinculante, tendo, à frente, se constituído verdadeiro marco para a produção de futuros tratados regionais sobre direitos humanos, bem como tendo sido reconhecida por órgãos de proteção de direitos humanos como detentora de efeitos vinculantes. Porém, foi o Protocolo de Buenos Aires de 1967, instrumento jurídico obrigatório, promulgado no Brasil pelo Decreto n. 67.542/1970, que absorveu, expressamente, os conteúdos contidos na DADDH e na Carta da OEA, dotando-os de valor normativo.

Outros tratados de efeito vinculante - convenções, pactos e protocolos —, que versam sobre direitos hu-

11 SECCHI, Leonardo. Políticas Públicas: conceitos, esquemas de análise, casos práticos. São Paulo: Cengage Learning, 2011. p. 33-58. 12 MIRANDA, Mariana Almeida Picanço de; CUNHA, José Ricardo. Poder Judiciário brasileiro e a proteção dos direitos humanos: aplicabilidade e incorporação das decisões da Corte Interamericana de Direitos Humanos. Rio de Janeiro: Escola de Direito do Rio de Janeiro da Fundação Getúlio Vargas, 2010. manos, em nível regional, passaram a ser discutidos e aprovados pela OEA, iniciando-se essa nova fase pela Convenção Americana de Direitos Humanos de 1969, que funciona como um código de direitos humanos e promove um constitucionalismo regional nas Américas, servindo como paradigma normativo a partir do qual os órgãos de monitoramento regional operarão. ${ }^{13}$ A Convenção somente passou a vigorar em 1978, por ocasião da ratificação do décimo primeiro país, tendo como seu objetivo primordial a instituição de órgãos com competência para supervisionar a atuação dos países integrantes em relação aos direitos humanos. O Brasil, a seu turno, apenas ratificou o Tratado em 1992, muito tempo após a sua entrada em vigor, o que ocorreu, somente, após e em razão de sua redemocratização.

A Convenção Americana, em sua parte II, deu os contornos atuais do Sistema Interamericano, que passou a ser composto pela Comissão e Corte Interamericanas, ambos os órgãos da OEA com atribuições fixadas pelo Tratado internacional. Em suma, ambos os órgãos têm, em comum, a função de supervisionar o cumprimento pelos Estados-membros da OEA das obrigações assumidas com a assinatura da Convenção Americana.

\subsection{Comissão Interamericana}

A sede da Comissão Interamericana situa-se em Washington, EUA, mesmo local onde funciona a da OEA. É composta por sete membros eleitos a título pessoal, mas vindos de países-membros da OEA, com os quais não guardam vínculos durante a atuação, visto que não são representantes de seus países de origem, restringindo-se suas funções a garantir a observância dos direitos humanos pelos Estados-Membros. Apesar disso, são impedidos de atuar em casos envolvendo o seu país de origem. Os integrantes são escolhidos pela Assembleia-Geral da OEA, para mandato de quatro anos, prorrogável pelo mesmo período. ${ }^{14}$

A competência primordial da Comissão Interamericana, prevista no artigo 41 da Convenção Americana, se divide, sucintamente, em duas: a) o recebimento de petições individuais, dando conta da violação a algum

13 PIOVESAN, Flávia Cristina. Direitos humanos e diálogo entre jurisdições. Revista Brasileira de Direito Constitucional, São Paulo, n. 19, p. 67-93, jan./jul. 2012.

14 ORGANIZAÇÃO DOS ESTADOS AMERICANOS. Comissão Interamericana de Direitos Humanos. 2015. Disponível em: http:// www.oas.org/pt/cidh/. Acesso em: 30 out. 2017. 
dos artigos da Convenção Americana ou de outros tratados de alcance regional, para a adoção de providências; b) e feitura de relatórios e recomendações sobre os direitos humanos no continente, os quais podem se limitar a um tema ou região específicos.

No que toca aos relatórios, é possível à Comissão Interamericana emitir relatórios anuais sobre a situação dos direitos humanos, periodicamente levados à Assembleia-Geral da OEA.

Também, a Comissão Interamericana detém, entre suas faculdades, o poder de realizar visitas "in loco", quando julga indispensável que um de seus membros faça, pessoalmente, uma verificação de condições a ela relatadas, ou, ainda, para fazer uma missão de verificação geral.

A Comissão Interamericana não possui competência para emitir sentenças e resolver de modo definitivo os conflitos a ela submetidos. Ao se deparar com violações a direitos garantidos no âmbito da OEA, a Comissão Interamericana redige um relatório final com recomendações ao Estado, visando retornar ao estado anterior ao ilícito, ou cessar imediatamente a violação e reparar/ indenizar o ofendido por todos os prejuízos sofridos, ou ainda, nas palavras da Convenção Americana, "determina que se assegure ao prejudicado o gozo do seu direito ou liberdade violados". Se entender necessário, poderá a Comissão submeter o caso à apreciação da Corte Interamericana, requerendo a emissão de decisão com efeitos jurídicos contra o Estado responsável pela violação de direitos humanos.

Considerando-se a importância das funções que a Comissão Interamericana exerce, não é demasiado afirmar que se trata do "Ministério Público" do Sistema Interamericano, "pela independência com que atua, por possuir legitimidade para agir perante a Corte Interamericana e também por ser chamada a intervir em todos os casos em trâmite perante esse órgão, na qualidade de órgão de representação de todos os membros da OEA". ${ }^{15}$

\subsection{Corte Interamericana}

O Órgão jurisdicional do Sistema Interamericano é a Corte Interamericana. Seus membros são designados

15 JAYME, Fernando Gonzaga. Direitos Humanos e sua efetivacão pela Corte Interamericana de Direitos Humanos. Belo Horizonte: Del Rey, 2005. juízes, com competência para proferirem sentenças de modo definitivo e inapelável, tudo nos termos do Pacto de São José da Costa Rica. Ademais, suas decisões são vinculantes, de modo que os Estados-membros que se comprometeram a respeitar sua jurisdição não podem se recusar a cumpri-las.

Diversamente do que ocorre com a Comissão Interamericana, em que as atribuições são efeito automático da aprovação ou adesão do Estado à Convenção Americana, para que a Corte Interamericana tenha competência jurisdicional sobre determinado país, faz-se necessário que este aceite a função contenciosa do órgão, com manifestação de vontade expressa nesse sentido, a ser depositada na sede da OEA, em conformidade com o que estabelece o artigo 62 da Convenção Americana. O Brasil, embora tenha adotado - ratificado - a Convenção Americana em 1992, e, por consectário legal, se sujeitado ao monitoramento pela Comissão Interamericana, apenas permitiu ser jurisdicionado pela Corte Interamericana em dezembro de 1998, por intermédio do Decreto Legislativo n. 88/1998.

A sentença da lavra da Corte Interamericana, nos dizeres da Convenção Americana, notadamente do artigo 68, 1 e 2, deve ser executada no plano interno como se produzida pelo direito interno.

Ao lado da função jurisdicional e contenciosa, a Corte Interamericana emite os denominados pareceres consultivos, tornando pública e obrigatória a sua interpretação concernente a dispositivos previstos nos tratados regionais de direitos humanos, definindo sentido e alcance das normas em questão, tudo em conformidade com o Regulamento da Corte Interamericana, aprovado em 2009.

\subsection{O Sistema Interamericano como mecanismo de controle da atuação dos Estados nacionais}

Como visto, o Sistema Interamericano, formado pelas Comissão e Corte Interamericanas, por iniciativa daquela instituição quase jurisdicional e por decisão final desse órgão judicial, tem atribuições de supervisionar os Estados, podendo reconhecer ilicitudes no tocante a direitos humanos, levadas a cabo por ação ou omissão do poder público doméstico, bem como impor obrigações aos entes estatais, a fim de reparar, indenizar, punir adequadamente os responsáveis pelos ilícitos contra direitos humanos e evitar a repetição das violações dos direitos humanos. 
Logo, trata-se de um mecanismo de controle judicial, que pode atuar não apenas em relação a condutas comissivas ou omissivas em sentido estrito dos Estados, como também no tocante a políticas públicas que, de alguma maneira, se mostrem nocivas a direitos humanos, ofendendo de modo grave as pessoas humanas. Assim, ao menos em tese, é possível cogitar-se que o mesmo fenômeno verificado em nível doméstico - no caso brasileiro - , acima descrito, segundo o qual o poder judiciário nacional estaria se imiscuindo em políticas públicas, não apenas as supervisionando e as declarando antinormativas - e, portanto, nulas - , senão atuando como órgão gerador de algumas dessa políticas, esteja a ocorrer no âmbito interamericano. Assim, exsurge o questionamento: está o Sistema Interamericano influenciando ou até mesmo criando políticas públicas no âmbito do Brasil?

\section{O Sistema INTERAMERICANO E O CONTROLE DE POLÍTICAS PÚBLICAS}

Nos capítulos anteriores, discorreu-se sobre as políticas públicas e o Sistema Interamericano, indicando-se que são, originariamente, legitimados para as formularem e executá-las os poderes legislativo e executivo. Todavia, em casos excepcionais, sobretudo no Brasil, o poder judiciário tem interferido em políticas públicas. Tal fenômeno, possivelmente, estaria a se repetir no âmbito internacional, mais precisamente no Sistema Interamericano, que tem funções jurisdicionais e de controle. Portanto, surge a necessidade de se investigar se o Sistema Interamericano está influenciando políticas públicas no Brasil e, principalmente, se está produzindo políticas públicas. Se sim, serão analisadas quais tipos e quais etapas das políticas públicas são levadas a efeito.

Para responder a tal problema, o presente trabalho investigará os sete julgados da Corte Interamericana sobre casos oriundos do Brasil, a fim de buscar, sobretudo no dispositivo deles, determinações impostas ao Estado brasileiro e identificar, à luz dos aportes teóricos trazidos no capítulo 2 deste artigo, se tais manifestações podem ser classificadas como interferências em políticas públicas brasileiras ou, até mesmo, como fatos geradores de políticas públicas a serem adotadas no e pelo Brasil.

\subsection{As decisões da Corte Interamericana sobre o Brasil}

O primeiro julgado a ser analisado é o mais recente, relativo ao caso Favela Nova Brasília vs. Brasil e proferido em 16 de fevereiro de $2017 .{ }^{16}$ Os fatos analisados dizem respeito a falhas e à demora na investigação e punição dos responsáveis por prováveis execuções extrajudiciais de 26 pessoas no âmbito das incursões policiais feitas pela Polícia Civil do Rio de Janeiro em 18 de outubro de 1994 e em oito de maio de 1995 na Favela Nova Brasília. Tais mortes, à época, foram justificadas pelas autoridades policiais mediante o uso de autos de resistência, não tendo sido investigados adequadamente. Apenas se estigmatizaram e se revitalizaram as pessoas falecidas, pois o foco teria sido dirigido à sua culpabilidade e não à verificação da legitimidade do uso da força, de modo que até o dia da decisão na Corte Interamericana as investigações não chegaram a conclusões, tampouco as vítimas e familiares tiveram seus danos reparados. Não foram, outrossim, investigados os fatos relativos à primeira incurso, em relação à tortura $\mathrm{e}$ à violência sexual por parte de agentes policiais contra três mulheres, duas delas adolescentes.

No caso em questão, a Corte Interamericana declarou a responsabilidade internacional do Estado brasileiro pela violação do direito às garantias judiciais de independência e imparcialidade das investigações, devida diligência e prazo razoável, do direito à proteção judicial e do direito à integridade pessoal.

Ainda, o Tribunal determinou a adoção das seguintes medidas de reparação às vítimas: i) continuar (no caso das mortes de 1994) e iniciar (no caso das mortes de 1995) de modo eficaz a investigação criminal em curso, em prazo razoável, para identificar, processar e, caso seja pertinente, punir os responsáveis; ii) avaliar se os fatos referentes às incursões de 1994 e 1995 devem ser objeto de pedido de Incidente de Deslocamento de Competência; iii) iniciar uma investigação eficaz a respeito dos fatos de violência sexual; iv) oferecer, gratuitamente, por meio de suas instituições de saúde especializadas, preferencialmente indicadas pelas vítimas, tratamento psicológico e psiquiátrico; v) realizar um ato público de reconhecimento de responsabilidade inter-

16 CORTE INTERAMERICANA DE DIREITOS HUMANOS. Caso Favela Nova Brasília versus Brasil. 2017. Disponível em: http://www.corteidh.or.cr/docs/casos/articulos/seriec_149_por. pdf. Acesso em: 12 out. 2017. 
nacional em relação aos fatos do presente caso e sua posterior investigação, durante o qual deverão ser inauguradas duas placas em memória das vítimas da presente Sentença, na praça principal da Favela Nova Brasília; vi) publicar, anualmente, um relatório oficial com dados relativos às mortes ocasionadas durante operações da polícia em todos os estados do país e com informação atualizada anualmente sobre as investigações realizadas a respeito de cada incidente que redunde na morte de um civil ou de um policial; vii) estabelecer os mecanismos normativos necessários para que, na hipótese de mortes, tortura ou violência sexual decorrentes de intervenção policial, em que prima facie policiais apareçam como possíveis acusados, desde a notitia criminis se delegue a investigação a um órgão independente e diferente da força pública envolvida no incidente, como uma autoridade judicial ou o Ministério Público, assistido por pessoal policial, técnico criminalístico e administrativo alheio ao órgão de segurança a que pertença o possível acusado, ou acusados; viii) adotar as medidas necessárias para que o Estado do Rio de Janeiro estabeleça metas e políticas de redução da letalidade e da violência policial; ix) implementar, em prazo razoável, um programa ou curso permanente e obrigatório sobre atendimento a mulheres vítimas de estupro, destinado a todos os níveis hierárquicos das Polícias Civil e Militar do Rio de Janeiro e a funcionários de atendimento de saúde; x) adotar as medidas legislativas, ou de outra natureza, necessárias para permitir às vítimas de delitos ou a seus familiares participar de maneira formal e efetiva da investigação de delitos conduzida pela polícia ou pelo Ministério Público; xi) adotar as medidas necessárias para uniformizar a expressão "lesão corporal ou homicídio decorrente de intervenção policial" nos relatórios e investigações da polícia ou do Ministério Público em casos de mortes ou lesões provocadas por ação policial. O conceito de “oposição" ou "resistência" à ação policial deverá ser abolido; e xiv) pagar as quantias fixadas na Sentença, a título de indenizações por dano imaterial.

O segundo é o caso Trabalhadores da Fazenda Brasil Verde, julgado pela Corte Interamericana em 20 de outubro de 2016. A base fática da respectiva sentença envolve a constatação de trabalho forçado e servidão por dívidas dos empregados na citada fazenda, em que havia ameaças de morte aos que conseguiam fugir do local, e o desaparecimento de dois jovens no mesmo contexto. Tal realidade foi verificada em um pano de fundo histórico e social, segundo os quais milhares de trabalhadores eram submetidos a trabalho escravo no Brasil. Na fazenda, constatou-se o impedimento aos empregados de saírem livremente, a falta de salário ou a existência de um salário ínfimo, o endividamento com o patrão fazendeiro, a falta de moradia, alimentação e saúde dignas. A situação foi atribuída ao Estado brasileiro, pois este teve conhecimento da existência dessas práticas em geral, especificamente, na Fazenda Brasil Verde, desde 1989 e, apesar disto, não adotou as medidas razoáveis de prevenção e resposta, tampouco forneceu às vítimas um mecanismo judicial efetivo para a proteção de seus direitos, a punição dos responsáveis e a obtenção de alguma reparação. Por fim, o Estado não adotou providências quanto ao desaparecimento de dois adolescentes na fazenda, o que foi denunciado a autoridades estatais em 21 de dezembro de 1988, sem, contudo, medidas efetivas serem adotadas para determinar o paradeiro de ambos. ${ }^{17}$

A Corte Interamericana reconheceu que o Estado é responsável pela violação do direito a não ser submetido a escravidão e ao tráfico de pessoas, das garantias judiciais de devida diligência e de prazo razoável e do direito à proteção judicial. Em virtude disso, impôs ao Brasil: i) reiniciar, com a devida diligência, as investigações e/ou processos penais relacionados aos fatos constatados no presente caso para, em um prazo razoável, identificar, processar e, se for o caso, punir os responsáveis; ii) publicar a sentença interamericana; iii) adotar as medidas necessárias para garantir que a prescrição não seja aplicada ao delito de Direito Internacional de escravidão e suas formas análogas; e iv) pagar valores a título de indenizações por dano imaterial.

Em 24 de novembro de 2010, foi julgado pela Corte Interamericana o caso Guerrilha do Araguaia. ${ }^{18}$ Tratou-se da detenção arbitrária, tortura e desaparecimento forçado de 70 pessoas, entre membros do Partido Comunista do Brasil e camponeses da região, em função de operações do Exército brasileiro empreendidas entre 1972 e 1975, com o objetivo de erradicar a Guerrilha do Araguaia, no contexto da ditadura militar do Brasil (1964-1985), bem como da Lei no 6.683/79, que impe-

17 CORTE INTERAMERICANA DE DIREITOS HUMANOS. Caso Trabalhadores da Fazenda Brasil Verde versus Brasil. 2016. Disponível em: http://portal.mj.gov.br/sedh/oea/garibaldi.pdf. Acesso em: 21 set. 2017.

18 CORTE INTERAMERICANA DE DIREITOS HUMANOS. Caso Gomes Lund e outros ("Guerrilha do Araguaia") versus Brasil. 2010. Disponível em: http://portal.mj.gov.br/sedh/oea/garibaldi.pdf. Acesso em: 21 ago. 2015. 
diu o Estado de levar a efeito uma investigação penal com a finalidade de julgar e punir as pessoas responsáveis pelos fatos em análise.

A Corte Interamericana reconheceu a ilicitude da situação de silêncio e impunidade no tocante às graves violações de direitos humanos praticadas durante o período da ditadura militar brasileira, declarando que o Estado é responsável pela violação dos direitos estabelecidos nos artigos 3 (direito ao reconhecimento da personalidade jurídica), 4 (direito à vida), 5 (direito à integridade pessoal), 7 (direito à liberdade pessoal), 8 (garantias judiciais), 13 (liberdade de pensamento e expressão) e 25 (proteção judicial), da Convenção Americana. Por fim, determinou que o Brasil i) conduza, eficazmente, perante a jurisdição ordinária, a investigação penal dos fatos do presente caso a fim de esclarecê-los, determinar as correspondentes responsabilidades penais e aplicar, efetivamente, as sanções, desconsiderando impedimentos legais a tanto; ii) empreenda todos os esforços para determinar o paradeiro das vítimas desaparecidas e, se for o caso, identificar e entregar os restos mortais a seus familiares; iii) ofereça tratamento médico e psicológico ou psiquiátrico que as vítimas requeiram em instituições públicas e, se for o caso, pagar os custos de tratamento em rede particular; iv) publique a sentença; v) realize um ato público de reconhecimento de responsabilidade internacional a respeito dos fatos do presente caso; vi) prossiga com ações desenvolvidas em matéria de capacitação e implemente, em um prazo razoável, um programa ou curso permanente e obrigatório sobre direitos humanos, dirigido a todos os níveis hierárquicos das Forças Armadas; vii) tipifique o delito de desaparecimento forçado de pessoas em conformidade com os parâmetros interamericanos, continuando, antes disso, a adotar todas aquelas ações que garantam o efetivo julgamento e, se for o caso, a punição em relação aos fatos constitutivos de desaparecimento forçado por meio dos mecanismos existentes no direito interno; viii) continuar iniciativas de busca, sistematização e publicação de toda a informação sobre a Guerrilha do Araguaia, assim como da informação relativa a violações de direitos humanos ocorridas durante o regime militar; e ix) pagar indenização por dano material e dano imaterial às vítimas.

Em 23 de setembro de 2009, a Corte Interamericana julgou o caso Garibaldi, que se refere ao homicídio do Senhor Sétimo Garibaldi, ocorrido em 27 de novembro de 1998, em uma operação extrajudicial de despejo das famílias de trabalhadores sem-terra, que ocupavam uma fazenda no Município de Querência do Norte, Estado do Paraná, que não foi investigado de modo diligente e dentro de um prazo razoável. ${ }^{19}$

Assim, entendeu a Corte Interamericana que o Estado brasileiro é responsável pela violação dos artigos 8 (Garantias Judiciais) e 25 (Proteção Judicial) da Convenção Americana, razão por que condenou o Brasil a adotar as seguintes medidas de reparação: i) como medidas de satisfação e não repetição, determinou que investigasse, julgasse e sancionasse os responsáveis pelo homicídio em tela e por eventuais faltas funcionais em que podem ter incorrido os funcionários públicos a cargo do inquérito que investigou, sem sucesso, os fatos; ii) efetuasse pagamento a título de dano moral e material às vítimas, parentes da pessoa assassinada.

Meses antes, mais precisamente no dia 6 de julho de 2009, a Corte Interamericana enfrentou o caso Escher, cujo contexto fático envolvia uma interceptação e monitoramento ilegal das linhas telefônicas de trabalhadores rurais, realizados entre abril e junho de 1999, pela Polícia Militar do Estado do Paraná, além da divulgação indevida das conversas telefônicas e da denegação da justiça e da reparação adequada às vítimas. Inexistiu investigação dos responsáveis pela primeira divulgação das conversas telefônicas; bem assim se verificou ausência de motivação da decisão em sede administrativa relativa à conduta funcional da juíza que autorizou a interceptação telefônica. ${ }^{20}$

Assim, a Corte Interamericana declarou que o Estado é responsável pela violação dos artigos 8.1 (Garantias Judiciais), 11 (vida privada, honra e reputação), 16 (Liberdade de Associação) e 25 (Proteção Judicial) da Convenção Americana. Determinou, pois, ao Estado brasileiro que: i) publicasse a sentença; ii) investigasse os fatos que geraram as violações do caso; iii) efetuasse o pagamento de valores fixados a título de danos imateriais às vítimas.

No Caso Nogueira de Carvalho ${ }^{21}$, julgado em 28 de

19 CORTE INTERAMERICANA DE DIREITOS HUMANOS Caso Garibaldi e outros versus Brasil. 2009. Disponível em: http://portal.mj.gov.br/sedh/oea/garibaldi.pdf. Acesso em: 21 set. 2017.

20 CORTE INTERAMERICANA DE DIREITOS HUMANOS. Caso Escher e outros versus Brasil. 2009. Disponível em: http://portal. mj.gov.br/sedh/oea/garibaldi.pdf. Acesso em: 21 set. 2017.

21 CORTE INTERAMERICANA DE DIREITOS HUMANOS. Caso Nogueira de Carvalho versus Brasil. 2006. Disponível em: $<$ http://portal.mj.gov.br/sedh/oea/garibaldi.pdf>. Acesso em: 21 
novembro de 2006, o Brasil foi absolvido pela Corte Interamericana, que entendeu inexistir suficiente comprovação de falta por parte do Estado quanto aos deveres de investigar e, eventualmente, punir os responsáveis pela prática de homicídio. Assim, não se fazem necessárias maiores explicações sobre o julgado, sobretudo porque ao Brasil não foi imposta nenhuma obrigação.

Por fim, o caso Ximenes Lopes, com sentença de 4 de julho de 2006, envolveu uma vítima, pessoa com deficiência mental, que foi submetida a condições desumanas e degradantes, que a levaram a óbito, por parte dos funcionários da casa de repouso em que estava em tratamento psiquiátrico, o que acabou não sendo investigado de modo minimamente eficaz. ${ }^{22}$

À luz de tal pano de fundo, a Corte Interamericana considerou o Estado brasileiro responsável pela violação dos direitos consagrados nos artigos 4 (Direito à Vida), 5 (Direito à Integridade Pessoal), 8 (Garantias Judiciais) e 25 (Proteção Judicial) da Convenção Americana. Portanto, condenou o Brasil às seguintes obrigações: i) garantir que o processo interno destinado a investigar e sancionar os responsáveis pelos fatos surta seus devidos efeitos; ii) publicar em jornal de grande circulação e no Diário oficial, a sentença interamericana; iii) desenvolver um programa de formação e capacitação para o pessoal médico, de psiquiatria e psicologia, de enfermagem e auxiliares de enfermagem e para todas as pessoas vinculadas ao atendimento de saúde mental, em especial sobre os princípios que devem reger o trato das pessoas portadoras de deficiência mental, conforme os padrões internacionais sobre a matéria; iv) e pagar em dinheiro indenização a familiares da vítima por danos materiais e imateriais.

\subsection{Avaliação dos julgados interamericanos à luz dos marcos conceituais das políticas públicas}

A respeito das medidas impostas pela Corte Interamericana nos seis casos vistos, em que houve condenação do Brasil, a vertente pesquisa visa responder se há alguma delas que configure política pública, de acordo com os conceitos apresentados na primeira parte deste artigo.

ago. 2017.

22 CORTE INTERAMERICANA DE DIREITOS HUMANOS. Caso Ximenes Lopes versus Brasil. 2006. Disponível em:http://portal. mj.gov.br/sedh/oea/garibaldi.pdf. Acesso em: 21 ago.2017.
A depender de cada um dos três conceitos de políticas públicas apresentados, é possível classificarem-se, diferentemente, as ordens emanadas pela Corte Interamericana.

Para o primeiro conceito, que entende como política pública uma ação intencional do Estado diante de um problema, é possível classificar todas as ordens da Corte Interamericana, com vistas a resolver um problema como uma política pública. O conceito se afigura abrangente, de modo a englobar praticamente todas as iniciativas do Sistema Interamericano em relação ao Brasil.

Para torná-lo um pouco mais rigoroso e estrito, o autor acrescentará a ele a necessidade de que traga alguma novidade às práticas domésticas brasileiras, alterando o rumo das manifestações do poder público pátrio, o que diminuirá o número de ordens da Corte Interamericana que se encaixarão nesse conceito, ainda amplo de política pública. Em outras palavras, só se estará diante de uma política pública, em sentido lato, quando uma determinação da Corte Interamericana específica puder ser reiterada em diversos casos pelo Brasil, sendo utilizada em situações similares, por autoridades locais, que a manejarão como precedente, desde que haja alguma inovação em relação ao tratamento que o poder público brasileiro daria ao caso.

Já para o segundo conceito, que enfoca as razões e finalidades que deram amparo às medidas, também é possível catalogar muitas das manifestações da Corte Interamericana como políticas públicas, tal como já feito no primeiro conceito, porque, nos casos analisados, restou evidente os motivos por que foram emitidas as ordens, os problemas a serem solucionados e as pessoas a se beneficiarem. Toda a extensa fundamentação dos julgados caminha nesse sentido. Portanto, não se afinou a peneira conceitual, continuando a passar o que já havia passado pelo primeiro filtro do primeiro conceito de políticas públicas.

Por terceiro, diante do conceito de política pública como sendo um conjunto de ações planejadas, com etapas, metas e resultados a serem atingidos - conceito mais estrito —, várias das medidas impostas pela Corte Interamericana não podem ser arroladas como políticas públicas em sentido estrito. Sendo no máximo quase políticas públicas em sentido estrito. Isso porque não se pode negar que há a criação de verdadeiros programas por parte de comandos oriundos de decisões da Corte Interamericana, que, porém, não traçam os métodos a 
serem utilizados, os resultados perseguidos e os meios de revisão e avaliação.

Esta, portanto, é a tipologia conceitual a ser utilizada para avaliar as prestações a que a Corte Interamericana condenou o Brasil.

Assim, os itens $\mathrm{iv}^{23}, \mathrm{v}^{24} \mathrm{e} \mathrm{xiv}^{25}$, a respeito do caso $\mathrm{Fa}$ vela Nova Brasília; iii ${ }^{26}$ e iv, sobre o caso Trabalhadores da Fazenda Brasil Verde; i, iv, v e ix, do caso Guerrilha do Araguaia; ii, acerca do caso Garibaldi; i e iii, sobre o caso Escher; e ii e iv, no tocante ao caso Ximenes Lopes, podem ser classificados como manifestações com potencial para interferir em políticas públicas, visto que se tratam de medidas para os casos concretos, que, podem ser replicadas a outras situações similares ocorridas no território doméstico, modificando o agir do poder público nacional. Não há política pública, mas apenas possibilidade de influência em políticas públicas brasileiras.

Já os itens vi e vii, do caso Favela Nova Brasília; e viii, do caso Guerrilha do Araguaia, estabelecem programas que se aproximariam um pouco mais do que se entende por política pública em sentido amplo, com efeitos gerais a todo o Brasil e com ares de inovação, faltando, todavia, pormenorizar as metas diretas e indiretas, os meios a serem utilizados e os mecanismos de avaliação. Portanto, há algumas medidas que se encaixam nos dois primeiros conceitos de políticas públicas, mas não atendem a todas as fases das políticas públicas, razão pela qual não se subsomem ao terceiro e mais preciso conceito.

Ainda, outros itens ${ }^{27}$

apresentam uma peculiaridade interessante, a saber: são requisições para que o Estado brasileiro adote políticas públicas com vistas a resolver determinados problemas. Não são políticas públicas, nem sequer pro-

23 A imposição diz respeito apenas ao caso concreto, mas se revela originária, por permitir às vítimas escolherem a instituição onde serão atendidas. Semelhante tratamento, pelo princípio da igualdade, poderá ser exigido por vítimas que estejam em situação similar às do caso interamericano em apreço, o que poderá criar nova política pública no Brasil de atendimentos de saúde fornecidos pelo Estado por meio de instituições particulares eleitas pela ofendida.

24 Também se verifica tratamento ao caso concreto, com ares de novidade, que poderá ser replicado em casos similares.

25 Valores de indenização às vítimas do caso concreto, que podem servir como paradigma a casos similares.

26 A imprescritibilidade, para casos envolvendo crimes ligados à escravidão e suas formas análogas, não tem sido adotada no Brasil.

27 Viii, ix e x, do caso Favela Nova Brasília; ii, vi e vii, do caso Guerrilha do Araguaia; e iii, do caso Ximenes Lopes. gramas, mesmo que incompletos, mas, sim, chamados impositivos à produção e implementação delas.

À derradeira, os pontos i, ii, iii, do caso Favela Nova Brasília; i e ii, do caso Trabalhadores da Fazenda Brasil Verde; iii, do caso Guerrilha do Araguaia; i, do caso Garibaldi; ii, do caso Escher; e i, do caso Ximenes Lopes, não cuidam de política pública em sentido amplo. Igualmente, inexiste possibilidade de interferências em políticas públicas, nem se trata de chamamento à criação dela, cuidando-se, apenas, de ordens esparsas e específicas aos casos concretos, sem nenhuma novidade ao sistema doméstico que possa irradiar efeitos para além do caso específico.

No tocante à classificação das políticas públicas nos tipos definidos por Theodore Lowi ${ }^{28}$, conforme o que se viu das prestações ordenadas pela Comissão Interamericana ao Estado brasileiro, é possível classificá-las, se entendidas como políticas públicas — tanto em sentido amplo, como em estrito - , como sendo sempre do tipo regulatório.

Por fim, no que se refere às etapas pelas quais se projetam, se deliberam, se aplicam e se revisam as políticas públicas $^{29}$, as determinações por parte da Comissão Interamericana lançadas em direção do poder público do Brasil se inserem nas fases da definição da avaliação e escolha das opções.

A definição da agenda acaba sendo feita ou pelos peticionários que levaram o tema, com base em caso concreto, ao Sistema Interamericano, ou seja, inicialmente à Comissão Interamericana, ou por esse órgão interamericano que, de certa maneira, ao decidir por receber e dar andamento à petição, acaba por deliberar sobre a agenda de uma possível política pública a ser estabelecida, total ou parcialmente, pelo Sistema Interamericano.

Já a identificação das alternativas possíveis para a resolução de um problema recai sobre as partes da demanda interamericana, isto é, ou sobre a Comissão Interamericana, ou sobre o Estado ou sobre os representantes das vítimas, visto que são eles que apresentam pedidos a respeito de quais medidas prestacionais devem ser impostas pela Corte Interamericana aos Estados.

28 a) políticas públicas distributivas; b) políticas públicas redistributivas; c) políticas públicas regulatórias; e d) políticas públicas constitutivas.

29 a) definição de agenda; b) identificação de alternativas, avaliação e escolha das opções; c) implementação; e d) reavaliação. 


\section{Considerações finais}

A noção dos conceitos, tipologia e formas de classificação de políticas públicas tem alterado a visão pela qual se visualiza a atuação estatal em sentido lato, o que passa pelo exame das manifestações dos poderes legislativo, executivo e judiciário —, podendo-se ser lido como o sistema de justiça.

Atualmente, tem atuado em torno das políticas pública o sistema de justiça, não apenas controlando-as, como também, às vezes, formulando-as. $\mathrm{O}$ mesmo fenômeno tem se observado nos sistemas de justiça internacionais, que estão a supervisionar à atuação dos estados nacionais, como também a dar origem a determinados programas nas mais diversas áreas, o que não é diferente no Sistema Interamericano em direção do Brasil.

Assim, esta pesquisa busca responder, com base nos sete casos brasileiros julgados no mérito pela Corte Interamericana, se esta tem produzido políticas públicas a serem cumpridas pelo Brasil, ou ao menos se tem interferido em programas nacionais.

$\mathrm{O}$ artigo, conforme visto acima, respondeu que, em certa medida, é possível, sim, falar-se que o Sistema Interamericano tem influenciado as políticas públicas domésticas e, em certa medida, criado algumas políticas públicas em sentido amplo, mesmo incompletas. Assim, não tem elaborado políticas públicas em sentido estrito, com todas as suas facetas, fases e requisitos, mas, sim, tem gerado: i) medidas de interferência em políticas públicas, inovando na atuação estatal brasileira, ao prever medidas específicas aos casos concretos, que podem ser replicáveis a outros similares; ii) medidas de políticas públicas em sentido amplo, ainda que incompletas, uma vez que tem a Corte Interamericana criado verdadeiros programas gerais de atuação estatal, os quais, porém, não contemplam todas as etapas necessárias à vida de uma política pública; e c) conclamações, impositivas, ordenando ao Estado brasileiro que crie políticas públicas para resolver determinados problemas.

\section{REFERÊNCIAS}

BRASIL. Supremo Tribunal Federal. Acórdão na ADPF n. 45. Tribunal Pleno. Relator: Mello, Celso de. Brasília, 29 abril 2004. Disponível em: www.stf.jus.br/por$\mathrm{tal} /$ acordaodecisaoRelevante/verDecisaoRelevante. asp $?$ ministro $=28 \&$ retorno $=$ true. Acesso em: 5 out. 2017.

BUCCI, Maria Paula. O conceito de política pública em direito. In: BUCCI, Maria Paula (org.). Políticas Públicas, reflexões sobre o conceito jurídico. São Paulo: Saraiva, 2006.

COHEN, M. D.; MARCH, J. G.; OLSEN. A garbage can model of organizational choice. Administrative Science Quarterly, Ithaca (NY), v. 17, n. 1, p. 1-25, 1972.

CORTE INTERAMERICANA DE DIREITOS HUMANOS. Caso trabalhadores da fazenda Brasil Verde versus Brasil. 2016. Disponível em: <http://portal.mj.gov.br/ sedh/oea/garibaldi.pdf>. Acesso em: 21 set. 2017.

CORTE INTERAMERICANA DE DIREITOS HUMANOS. Caso Escher e outros versus Brasil. 2009. Disponível em: <http://portal.mj.gov.br/sedh/oea/garibaldi.pdf $>$. Acesso em: 21 set. 2017.

CORTE INTERAMERICANA DE DIREITOS HUMANOS. Caso favela Nova Brasilia versus Brasil. 2017. Disponível em http://www.corteidh.or.cr/docs/casos/ articulos/seriec_149_por.pdf. Acesso em: 12 out. 2017.

CORTE INTERAMERICANA DE DIREITOS HUMANOS. Caso Garibaldi e outros versus Brasil. 2009. Disponível em: http://portal.mj.gov.br/sedh/oea/garibaldi.pdf. Acesso em: 21 set. 2017.

CORTE INTERAMERICANA DE DIREITOS HUMANOS. Caso Nogueira de Carvalho versus Brasil. 2006. Disponível em: http://portal.mj.gov.br/sedh/oea/garibaldi.pdf. Acesso em: 21 ago.2017.

DYE, Thomas R. Understanding public policy. 12. ed. Prentice-Hall, Englewood Cliffs, N.J, 2008.

JAYME, Fernando Gonzaga. Direitos Humanos e sua efetivação pela Corte Interamericana de direitos humanos. Belo Horizonte: Del Rey, 2005.

MIRANDA, Mariana Almeida Picanço de; CUNHA, José Ricardo. Poder Judiciário brasileiro e a proteção dos direitos humanos: aplicabilidade e incorporação das decisões da Corte Interamericana de Direitos Humanos. Rio de Janeiro: Escola de Direito do Rio de Janeiro da Fundação Getúlio Vargas, 2010.

ORGANIZAÇÃO DOS ESTADOS AMERICANOS. Comissão Interamericana de Direitos Humanos. 2015. Disponível em: http://www.oas.org/pt/cidh/. Acesso em: 30 out. 2017. 
ORGANIZAÇÃO DOS ESTADOS AMERICANOS.

Direitos humanos e diálogo entre jurisdições. Revista

Brasileira de Direito Constitucional, São Paulo, n. 19, p. $67-$ 93, jan./jul. 2012.

PIOVESAN, Flávia Cristina. Direitos humanos e o direito constitucional internacional. 8. ed. São Paulo: Saraiva, 2007.

RODRIGUES, Marta M. Assumpção. Políticas Públicas. São Paulo: Publifolha, 2011. (Coleção Folha Explica).

SECCHI, Leonardo. Politicas públicas: conceitos, esquemas de análise, casos práticos. São Paulo: Cengage Learning, 2011.
SOUZA, Celina. Políticas públicas: uma revisão da literatura. Sociologias. Porto Alegre, ano 8, n. 16, jul./dez. 2006.

WU, X; RAMESH, M; HOWLLET, M; FRITZEN, S. Guia de políticas públicas: gerenciando processos. Tradução de Ricardo Avelar de Souza. Brasília: Enap, 2014. 
Para publicar na Revista de Direito Internacional, acesse o endereço eletrônico www.rdi.uniceub.br ou www.brazilianjournal.org.

Observe as normas de publicação, para facilitar e agilizar o trabalho de edição. 